\title{
Prevalence and associated factors of goiter among rural children aged 6-12 years old in Northwest Ethiopia, cross -sectional study
}

\author{
Molla Mesele ${ }^{1 *}$, Getu Degu ${ }^{2}$ and Haimanot Gebrehiwot ${ }^{3}$
}

\begin{abstract}
Background: Goiter, an indicator of chronic iodine deficiency, is a major public health problem for populations living with iodine deficient environment, particularly for young children. It is a threat to the social and economic development of many developing countries including Ethiopia. The aim of the study was to assess the prevalence and associated factors of goiter among rural children aged 6-12 years, Northwest Ethiopia.

Methods: A community based cross-sectional study was employed from July to December 2012 in Lay Armachiho district. A total of 698 children aged 6-12 years were included in the study. Multistage sampling was used. Children were examined for the presence/absence of goiter using a criterion set by World Health Organization. The level of lodine of the salt was estimated by using spot testing kits. Descriptive and summary statistics were employed. Bivariate and multivariate logistic regressions were used to identify associated factors. The degree of association was assessed by using Odds ratio with $95 \%$ confidence interval were computed to see the presence and strength of association.
\end{abstract}

Results: Totally 694 children were included in the analysis. The prevalence of goiter was found to be $37.6 \%$. Goiter of grade 1 was $28.5 \%$ and that of grade 2 was $9.1 \%$. 29.7\% of the samples had adequate iodine content. The age of child (AOR: 1.24,95\% Cl: 1.12, 1.36), being female $(A O R=1.98,95 \% \mathrm{Cl}: 1.38-2.85)$, salt iodine level ( $\mathrm{AOR}=0.44,95 \% \mathrm{Cl}$ : $0.27,0.71$ ), family history of goiter ( $\mathrm{AOR}=3.18,95 \% \mathrm{Cl}: 2.08,4.858$ ), fish consumption ( $\mathrm{AOR}=0.42,95 \% \mathrm{Cl} ; 0.22,0.80$ ) were factors associated with goiter.

Conclusion: Chronic iodine deficiency was a severe public health problem in the study communities. Ensuring the consumption of iodized salt and promotion of fish intake at the household level are highly recommended.

Keywords: Goiter, lodine deficiency, Children, Ethiopia

\section{Background}

Thyroid disorders are one of the most common endocrine problems in children and adolescents. Diagnostic approaches of thyroid disorders can be approached from the perspective of goiter [1]. The involvement of both dietary non dietary factors besides iodine deficiency might interact in the genesis of thyroid enlargement [2].

Goiter, an indicator of iodine deficiency, is a major public health problem for populations living in iodine deficient

\footnotetext{
* Correspondence: molmesele@gmail.com

'Department of Nutrition, Institute of Public Health, University of Gondar, Gondar, Ethiopia

Full list of author information is available at the end of the article
}

environment. Iodine deficiency during childhood would reduce somatic growth, cognitive and motor function $[3,4]$.

Iodine deficiency is characterized by a slowdown of metabolic processes that results in growth and development abnormality for children [5,6]. It has multiple adverse effects in humans, termed as an iodine deficiency disorders (IDDs). This problem is happened due to inadequate production of thyroid hormone [4]. Iodine deficiency is the most common cause of preventable mental retardation. Subsequently, it would pose a threat to the social and economic development of countries [7].

Controlled studies conducted in iodine-deficient regions have shown that iodine supplementation eliminated new cases of cretinism. Furthermore, it contributed for the

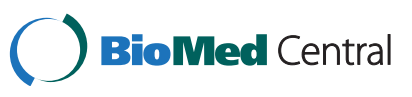


reduction of infant mortality and the improvement of cognitive function in the population [6].

School-age children are considered as an appropriate target group for determining iodine deficiency due to their susceptibility to iodine deficiency, easily accessibility as a study group and representativeness of their community society as a whole [8].

In the last two decades, the elimination of IDD has been considered as an integral part of many national nutrition strategies [9]. As a result, carefully monitored universal salt iodization program is the most effective strategy to control iodine deficiency. Achieving optimal iodine intake from iodized salt would minimize the amount of thyroid dysfunction in population $[4,10]$.

Globally, the Total Goiter Prevalence (TGP) in the general population is estimated to be $15.8 \%$, varying between 4.7\% in America to $28.3 \%$ in Africa [3]. Prevalence of goiter in children aged 6-12 years varies in different studies in the world. It was $22.3 \%$ in southern Sudan, $11.4 \%$ Rajasthan, and $20.5 \%$ in India [11-13].

Study on prevalence of goiter among children 6 to 12 years of age in Ethiopia by the year 2005 was 39.9\%, with rates of $27.7 \%$ for palpable, and $12.2 \%$ for visible goiter [14].

The prevalence of goiter was higher in females than males in different studies in the world $[13,15,16]$. Low dietary supply of iodine in areas where the soil has low iodine content is the main factor for development of Goiter. Fortification of salt with iodine is best method of preventing iodine deficiency in such kind of population $[3,17,18]$.

According to the demographic and health survey report of 2011 only 16 percent of children in Ethiopia live in households that utilized an iodised salt. The percentage is higher in urban areas than in rural areas $(24 \%$ compared with 14\%) [17].

Environmental goitrogens may cause goiter by acting directly on the thyroid gland, but they can also act indirectly by altering the regulatory mechanisms of the thyroid gland and the peripheral metabolism and excretion of thyroid hormones. Different studies suggested that intake of goitrogens in certain food items like millet, cow milk, cassava, cabbage, sorghum and water can cause goiter $[11,19,20]$.

Clinical examination of thyroid gland using the standard method which is one of the many approaches recommended by the joint WHO/UNICEF/ICCIDD consultation to identify IDD was used in the study. The other quantifiable indicators like UIE method and TSH were not considered in the study because they are costly and in accessible in poor settings, like Ethiopia.

IDD is more confined to mountainous regions were soil erosion and flooding is common. Lay Armachiho district is one of the mountainous areas in Ethiopia. This study assessed the prevalence of goiter and its associated factors among children of Lay Armachiho District.

\section{Methods}

A community based cross-sectional study design was employed in Lay Armachiho district, northwestern Ethiopia from July to December 2012.

Those rural children aged 6-12 in the selected kebeles in Lay Armachiho district were included in the study. Those children who were seriously ill at the time of study were excluded from the study.

Household was considered as a sampling unit. Children with age group 6-12 years who lived in the study area along with their mothers/caregivers were the study units. Sample size was calculated using single population proportion formula by assuming the prevalence of goiter in children aged 6-12 years $29.1 \%$ [21], with 95\% confidence interval, $5 \%$ absolute precision, $10 \%$ non response rate, and design effect of two, the total sample size was calculated to be 698 .

Multi stage sampling was employed. The first stage was kebele (the smallest administrative unit in Ethiopia), whereas household was second stage. Among 33 rural kebeles in the district, seven of them were selected by simple random sampling. In each kebele a number of households with probability proportional to size were allocated. Then systematic random sampling technique was employed to reach individual households. The first houses were identified from the central places which were kebele administrative offices. By rotating a pencil on a book, where the sharp end indicating was taken to be the first household. Data collectors counted the total number of houses between the kebele administrative offices and the boundary of the kebeles. The sampling interval was calculated. The subsequent households were selected by using the sampling intervals. Data collectors were continuing their interview until the calculated samples were obtained.

In this particular study, the presence of goiter was considered absent if no palpable or visible goiter (Grade 0), whereas goiter is present when the child has Grade 1 or grade 2 goiter or both. Iodine level of salt was adequate when its level was 15 PPM or more.

A pre-tested and structured questionnaire was used. Physical examination of the thyroid was done to identify the presence of goiter. Iodine level of the salt was determined by a rapid test kit. The test can be used semi -quantitatively to measure iodine in salt at 0,15 , and $\geq 15 \mathrm{ppm}$ depending on the intensity of the color obtained.

Six Health Officer supervised by 3 supervisors collected the data. Three days training was given before data collection. Pre-test of the instrument and the procedure was conducted on 34 households before the actual data collection. Physical examination of thyroid was performed by trained health officers and goiter was graded by using WHO grading system (Grade 0: no goiter, grade 1: palpable but not 
visible and Grade 2: visible). Salt at household level was measured by rapid MBI test kit. The data collector delivered one or two drops of the solution on a small salt sample (one teaspoon is adequate). The intensity of the blue color which develops indicates the salt iodine level.

First code was given to the completed questionnaire and then data were entered into EPI info version 3.5.3 statistical software and then transferred to SPSS version 20 statistical package for further analysis. Data cleaning were performed to check for accuracy and consistencies and missed values and variables. The results were presented in the form of tables, figures, and text. Both bivariate and multivariate logistic regressions were used to identify associated factors. Odds ratio with $95 \%$ confidence interval were used to identify the presence and strength of association.

Ethical clearance was obtained from the Institutional Ethical Review board of Institute of Public Health, College of Medicine and Health Sciences, University of Gondar. Written letters were offered from North Gondar Zonal Health Department. Verbal Informed consent was obtained from each mothers/caregivers before the start of the interview. Children were also asked for assent before palpation of their thyroid gland. Those children who were identified as having goiter were referred to health institutions to get appropriate treatment and support.

\section{Results and discussion}

\section{Socio demographic characteristics}

Out of 698 children, 694 children were included in the analysis (response rate $=99.42 \%$ ). The mean age of the study participants' was 8.6 years $(\mathrm{SD}=1.93)$. Three hundred twenty three $(46.5 \%)$ children were males. Majority (93.2\%) of mothers/caregivers were Orthodox Christians. Five hundred fifty nine $(80.5 \%)$ of mothers/caregivers were unable to read and write and 474(68.3\%) were house wives (Table 1).

This study showed that five hundred forty seven (78.8\%) of mothers/caregivers usually add salt late at the end of cooking. Most (87.5\%) of the mothers/caregivers did not expose salt to sunlight while 587 (84.6\%) of them covered the salt containers. Among household salt samples, iodine concentration varied from $0 \mathrm{ppm}$ to $30 \mathrm{ppm}$ by using MBI rapid test kits. Two hundred six (29.7\%) households used salt with adequate iodine level ( $\geq 15 \mathrm{ppm}$ ) (Table 2).

Millet and cabbage were goitrogens frequently eaten by children. Fish was also consumed by small number of children. Pond was their source of drinking water for majority $(65.9 \%)$ of participants (Table 3$)$.

\section{Prevalence of goiter}

The overall prevalence of goiter was found to be $37.6 \%$. Prevalence of Grade 1 goiter was $28.5 \%$ and that of grade 2 was $9.1 \%$. In terms of the WHO, UNICEF and ICCIDD criteria for assessing the severity of IDD using
Table 1 Socio-demographic characteristics of children and their mothers/caregivers at rural kebeles of Lay Armachiho district, Northwest Ethiopia, 2012 ( $N=694)$

\begin{tabular}{lll}
\hline Variables & Numbers & Percentage \\
\hline Sex of children & 323 & \\
Female & 371 & 46.5 \\
Male & & 53.5 \\
Marital status of mothers/caregivers & & \\
Single & 20 & 2.9 \\
Married & 569 & 82.0 \\
Divorced & 70 & 10.1 \\
Widowed & 35 & 5.0 \\
Ethnicity & & \\
Amhara & 337 & 48.6 \\
Tigre & 6 & 0.9 \\
Kimant & 351 & 50.6 \\
Religion & & \\
Orthodox & 647 & 93.2 \\
Muslim & 41 & 5.9 \\
Other* & 6 & 0.9
\end{tabular}

Educational status of mother/caregiver

Unable to read write $\quad 559 \quad 80.5$

Able to read write $\quad 50 \quad 7.2$

$\begin{array}{lll}\text { Primary education } & 65 & 9.4\end{array}$

$\begin{array}{lll}\text { Secondary education } & 14 & 2.0\end{array}$

$\begin{array}{lll}\text { Tertiary and above } & 6 & 0.9\end{array}$

Occupation of mother/caregiver

Housewife $\quad 474 \quad 68.3$

$\begin{array}{lll}\text { Farmer } & 96 & 13.8\end{array}$

Government employed $\quad 15 \quad 2.2$

$\begin{array}{lll}\text { Merchant } & 75 & 10.8\end{array}$

Day laborer $\quad 31 \quad 4.5$

$\begin{array}{lll}\text { Private employed } & 3 & 0.4\end{array}$

Kebele

\begin{tabular}{lll} 
Workmidir & 72 & 10.4 \\
Worangeb/Maura & 55 & 7.9 \\
Janicaw & 89 & 12.8 \\
Woynochrobit & 134 & 19.3 \\
Genbera & 110 & 15.9 \\
Chiranbezo & 132 & 19.0 \\
Aykuachakirn & 102 & 14.7 \\
\hline
\end{tabular}

*Protestant, Catholic.

prevalence of goiter, the prevalence in the study area could be seen as high and IDD was severe public health problem [8].

This finding was in agreement with findings of a national epidemiological goiter survey among children in 
Table 2 Knowledge and attitude of mothers on iodized salt and utilization of iodized salt in rural households, Lay Armachiho District, Northwest Ethiopia, 2012 ( $N=694)$

\begin{tabular}{|c|c|c|}
\hline Frequency & & Percent \\
\hline \multicolumn{3}{|l|}{ Type of salt used } \\
\hline Packed* & 28 & 4.22 \\
\hline Course (not packed) & 666 & 95.78 \\
\hline \multicolumn{3}{|l|}{ Time to add salt while cooking food } \\
\hline Early & 33 & 4.8 \\
\hline Middle & 95 & 13.7 \\
\hline Late/end & 547 & 78.8 \\
\hline After cooking & 14 & 2.0 \\
\hline Don't know/not sure & 5 & 0.7 \\
\hline \multicolumn{3}{|l|}{ Sun light exposure } \\
\hline Yes & 82 & 11.8 \\
\hline No & 607 & 87.5 \\
\hline \multicolumn{3}{|l|}{ How it stored (storage material) } \\
\hline Kept open (open container) & 101 & 14.6 \\
\hline Kept closed (closed container) & 587 & 84.6 \\
\hline Both & 5 & 0.8 \\
\hline \multicolumn{3}{|l|}{ Storage with relation to fire } \\
\hline Near to fire & 317 & 45.7 \\
\hline Away from fire & 372 & 53.6 \\
\hline Both & 5 & 0.7 \\
\hline \multicolumn{3}{|l|}{ Salt iodine level } \\
\hline 0 ppm & 260 & 37.5 \\
\hline 1-15 ppm & 228 & 32.8 \\
\hline 16-30 ppm & 206 & 29.7 \\
\hline
\end{tabular}

*Powdered salt in packaged material like plastic.

Ethiopia which was 39.9\% (95\%CI: $38.6 \%, 41.2 \%)$ [14] and in Sudan (38.8\%) [19].

The Prevalence in the current study was higher than in studies done at South Africa (25.5\%) [22], southern Blue Nile area of Sudan (22.3\%) [11], India (20.5\%) [12], Rajasthan (11.4\%) [13] but it was lower than a study done on schoolchildren in Islamabad which was $71.6 \%$ [23]. The Prevalence was also lower than the crosssectional study done among ten villages from four administrative regions of Ethiopia with a gross prevalence of goiter among school children of 53.3\% [20]. The reason may be due to the fact that our study was undertaken after universal salt iodization launched in Ethiopia.

The study revealed that prevalence of goiter was $98 \%$ higher among females when compared to that of males ( $\mathrm{AOR}=1.98$, 95\% CI: 1.38-2.85). This may be due to the fact that iodine requirement for female children were higher than males especially at the beginning of pubertal age. This is related to the difference in sex hormones and pubertal growth pattern among boys and girls in
Table 3 Dietary intake of children and consumption of goitrogens in rural children aged 6-12 in Lay Armachiho District, Northwest Ethiopia, 2012 ( $N=694$ )

\begin{tabular}{lll}
\hline & Frequency & Percent \\
\hline Millet consumption & & \\
At least once per day & 165 & 23.8 \\
At least once per week & 230 & 33.1 \\
At least once per month & 189 & 27.2 \\
Never & 110 & 15.6 \\
Dairy product consumption & & \\
At least Once per day & 128 & 18.4 \\
At least once per week & 206 & 29.7 \\
At least once per month & 102 & 14.7 \\
Never & 258 & 37.2 \\
Cabbage consumption & & \\
At least once per day & 42 & 6.3 \\
At least once per week & 216 & 30.9 \\
At least once per month & 198 & 28.5 \\
Never & 238 & 34.3 \\
Fish consumption & & \\
At least once per week & 44 & 6.8 .3 \\
At least once per month & 108 & 10.3 \\
Never & 542 & 78.09 \\
Source of drinking water & & \\
Pipe & 134 & \\
Bare hole & 457 & \\
River & & \\
Pond & & \\
\hline
\end{tabular}

higher age groups. This finding was similar with different studies $[13,15,16,20,21]$ but in a study conducted at Sudan and china there were no significant difference between boys and girls $[11,14,24]$.

\section{Factors associated with goiter}

For a unit increase in age, there was a 1.24 times increased risk of developing goiter in children (AOR: 1.24,95\% CI: 1.12, 1.36) (Table 4). This might be due to the fact that iodine requirement increases with age. Older children had prolonged exposure for iodine deficient environment and also universal salt iodization was implemented in the past few years and older ones are less benefited from the intervention. Thyroid size is correlated with body surface area and increases with age. Hence, enlarged thyroid could be more visible and palpable in elderly children. This finding was similar with study done in Lesotho [19] but it was different from in china which indicated no statistically significant difference among the goiter rates across the different age groups [24]. 
Table 4 Factors associated with goiter among rural children aged 6-12 in Lay Armachiho District, Northwest Ethiopia, $2012(N=694)$

\begin{tabular}{|c|c|c|c|c|}
\hline \multirow{3}{*}{ Variables } & \multicolumn{4}{|c|}{ OR $(95 \% \mathrm{Cl})$} \\
\hline & \multicolumn{2}{|c|}{ Goiter status } & \multirow[t]{2}{*}{ Crude OR $(95 \% \mathrm{Cl})$} & \multirow[t]{2}{*}{ Adjusted OR (95\% Cl) } \\
\hline & Yes & No & & \\
\hline \multicolumn{5}{|l|}{ Age } \\
\hline & 261 & 433 & $1.208(1.113,1.310)$ & $1.236(1.123,1.360)$ \\
\hline \multicolumn{5}{|l|}{ Sex of the child } \\
\hline Male & 93 & 230 & 1 & $1^{*}$ \\
\hline Female & 168 & 203 & $2.047(1.4922 .807)$ & $1.986(1.379,2.860)$ \\
\hline \multicolumn{5}{|l|}{ Type of salt used } \\
\hline Packed & 5 & 23 & 1 & 1 \\
\hline Course (not packed) & 256 & 410 & $2.872(1.078,7.650)$ & $2.708(0.868,8.452)$ \\
\hline \multicolumn{5}{|c|}{ Time to add salt during cooking } \\
\hline Early & 13 & 25 & 1 & $* *$ \\
\hline Middle & 23 & 72 & $0.614(0.271,1.392$ & \\
\hline Late end & 224 & 323 & $1.334(0.668,2.663)$ & \\
\hline After cooking & 1 & 13 & $0.148(0.017,1.259)$ & \\
\hline \multicolumn{5}{|c|}{ Storage with relation to fire } \\
\hline Near to fire & 139 & 183 & 1 & $* *$ \\
\hline Away from fire & 122 & 250 & $0.642(0.472,0.875)$ & \\
\hline \multicolumn{5}{|l|}{ Place of storage of salt } \\
\hline Kept open & 52 & 54 & $1.746(1.151,2.649)$ & $1.625(0.985,2.680)$ \\
\hline Kept closed & 209 & 379 & 1 & 1 \\
\hline \multicolumn{5}{|l|}{ Family history of goiter } \\
\hline Yes & 125 & 93 & $3.360(2.406,4.693)$ & $3.175(2.075,4.858)$ \\
\hline No & 136 & 340 & 1 & $1^{*}$ \\
\hline \multicolumn{5}{|l|}{ Kebele where the child live } \\
\hline Workmidir & 49 & 23 & $2.493(1.328,4.681)$ & $2.831(1.237,6.479)$ \\
\hline Worangeb/maura & 6 & 49 & $0.143(0.056,0.364)$ & $0.303(0.095,0.970)$ \\
\hline Janicaw & 24 & 65 & $0.432(0.235,0.794)$ & $0.565(0.260,1.230)$ \\
\hline Woynochrobit & 62 & 72 & $1.008(0.601,1.689)$ & $0.701(0.285,1.726)$ \\
\hline Genbera & 29 & 81 & $0.419(0.236,0.745)$ & $0.454(0.207,0.997)$ \\
\hline Chiranbezo & 44 & 88 & $0.585(0.344,0.996)$ & $1.704(0.602,4.822)$ \\
\hline Aykochakirn & 47 & 55 & 1 & $1^{*}$ \\
\hline \multicolumn{5}{|l|}{ Altitude in meter } \\
\hline$<1500 m$ & 96 & 78 & $2.462(1.54,3.936)$ & $* *$ \\
\hline $1500-2000 \mathrm{~m}$ & 53 & 146 & $0.726(0.450,1.173)$ & \\
\hline $2000-2500 \mathrm{~m}$ & 68 & 121 & $1.124(0.704,1.795)$ & \\
\hline$>2500 \mathrm{~m}$ & 44 & 88 & 1 & \\
\hline \multicolumn{5}{|l|}{ Knowledge on iodised salt } \\
\hline Not knowledgeable & 181 & 258 & 1 & $* *$ \\
\hline Knowledgeable & 80 & 175 & $0.652(0.470,0.902)$ & \\
\hline \multicolumn{5}{|c|}{ Attitude on iodised salt use } \\
\hline Favorable & 188 & 277 & 1 & $* *$ \\
\hline Not favorable & 73 & 156 & $0.689(0.494,0.963)$ & \\
\hline
\end{tabular}


Table 4 Factors associated with goiter among rural children aged 6-12 in Lay Armachiho District, Northwest Ethiopia, 2012 ( $N=694)$ (Continued)

\begin{tabular}{|c|c|c|c|c|}
\hline \multicolumn{5}{|l|}{ Millet consumption } \\
\hline At least once per day & 79 & 86 & 1 & $* *$ \\
\hline At least once per week & 60 & 170 & $0.384(0.251,0.587)$ & \\
\hline At least once per month & 82 & 107 & $0.834(0.548,1.269)$ & \\
\hline Never & 40 & 70 & $0.622(0.380,1.020)$ & \\
\hline \multicolumn{5}{|l|}{ Fish consumption } \\
\hline At least once per week & 5 & 39 & $0.214(0.083,0.552)$ & $0.400(0.131,1.224)$ \\
\hline At least once per month & 53 & 55 & $1.609(1.062,2.438)$ & $0.416(0.216,0.804)$ \\
\hline Never & 203 & 339 & 1 & $1^{*}$ \\
\hline \multicolumn{5}{|c|}{ Cereals commonly used by the child } \\
\hline Millet & 85 & 93 & 1 & 1 \\
\hline Teff & 15 & 35 & $0.469(0.239,0.919)$ & $0.596(0.276,1.289)$ \\
\hline Maize & 15 & 44 & $0.373(0.194,0.719)$ & $0.508(0.226,1.140)$ \\
\hline Wheat & 39 & 106 & $0.403(0.252,0.644)$ & $0.315(0.130,0.765)$ \\
\hline Oat & 2 & 4 & $0.547(0.98,3.063)$ & $0.538(0.069,4.173)$ \\
\hline \multicolumn{5}{|c|}{ lodine level of salt used by household } \\
\hline 0 ppm & 134 & 126 & 1 & $1^{*}$ \\
\hline $1-15 \mathrm{ppm}$ & 74 & 154 & $0.452(0.312,0.653)$ & $0.634(0.403,0.996)$ \\
\hline 16-30 ppm & 53 & 153 & $0.326(0.219,0.484)$ & $0.441(0.272,0.714)$ \\
\hline
\end{tabular}

*Significant from the multivariate logistic regression (Backward LR method).

**Not significant and fail to appear into the final multivariate logistic regression model.

Family history of goiter was significantly associated with goiter in this study. Children having goiter in first degree relative were 3.18 times more likely to develop goiter when compared with those who had no $(\mathrm{AOR}=$ 3.18,95\% CI: 2.08,4.86) (Table 4). This finding was in agreement with a survey of goiter in Brazil [25] and Ethiopia [26]. In a case control study in Germany, Patients with goiter had showed a significantly higher proportion of parents or siblings with goiter. Children from parents' with goiter showed a 2.7 fold increased risk of developing goiter [27]. Thus, the significantly higher rate of positive family histories of goiter in children indicates the importance of genetic factors in goiter development.

In this study the kebele where the child was living had independently associated with the development of goiter. Children who live in Workmidir kebele were 2.83 times more likely to have goiter than their counterparts in Aykuachakirn kebele ( $\mathrm{AOR}=2.83,95 \% \mathrm{CI}: 1.24,6.48)$ where as children in Genbera and Worangeb kebele were $54.6 \%$ and $69.7 \%$ less likely to have goiter when compared with their counterparts in Aykuachakirn respectively ((AOR $=0.454,95 \% \mathrm{CI}: 0.207,0.997),(\mathrm{AOR}=$ 0.30, 95\% CI: 0.095, 0.97)) (Table 4). Households using adequate salt iodine level in Workmidir and Aykuachakirn were low. Consumption of salt with inadequate iodine level may be the reason for increased risk of goiter in children of Aykuachakirn and Workmidir. Moreover increased consumption of fish by children in Genbera may contribute for decreased prevalence in children of this kebele.

Low dietary intakes of iodine contribute a lot for development of goiter. Hence Increasing dietary intake of iodine through consuming iodised salt is clearly the key towards eradication of goiter caused by iodine deficiency. Based on WHO recommendation salt iodine level should be adequate in $90 \%$ of households.

In Ethiopia efforts have been made to iodize the salt produced in Afdera and Dobi in Afar and Somali regions. The Federal Government of Ethiopia passed a mandatory salt regulation requiring all salt meant for human consumption to be iodized since March 2011 (33). Only 29.7\% of households were using adequately iodised salt in the study area. This finding was lower than a studies done in India $[12,16]$, But higher when compared with a national survey in Ethiopia (15\%) and Jodhpur district of Rajasthan ( 18.5\%) $[13,17]$.

Utilization of iodised salt in the households was independently associated with development of goiter in children. Using adequately iodized salt (16-30 ppm) was protective for goiter by $55.9 \%$ than using non iodized salt $(0 \mathrm{ppm})(\mathrm{AOR}=0.44,95 \% \mathrm{CI}: 0.27,0.71)$. Using salt with Iodine level of $1-15 \mathrm{ppm}$ was also protective for 
goiter by $36.6 \%$ while compared to using non iodised salt (0 ppm) $(\mathrm{AOR}=0.63,95 \% \mathrm{CI}: 0.40,0.99)$ (Table 4). This finding was similar with a study done on Qom city of Iran [20], But in a study on Isfaham city of Iraq there was no relationship between iodine intake and goiter [26].

In this study fish consumption at least once per month was $58.4 \%$ times protective for goiter than never taking fish at all $(\mathrm{AOR}=0.42,95 \% \mathrm{CI} ; 0.22,0.80)$ (Table 4). Foods of marine origin have higher iodine content because marine plants and animals concentrate iodine from seawater. So sea foods including fish are naturally high in there iodine content so fish consumption will increase daily intake of iodine [4,28].

Many studies on prevalence of goiter in Ethiopia were school based cross sectional surveys whereas the current study was community based. This study tried to include children who might not been enrolled in school or might have dropped out of school due to social stigma created by IDD. The study also differs from studies done before because it showed chronic iodine deficiency and determine recent iodine intake. The study also revealed the existence of severe iodine deficiency in the study area after Ethiopia launched universal salt iodization. But the study failed to determine the causal relationships between goiter and the predictor variables due to its cross-sectional nature. Inter observer Bias both in grading of goiter and determination of salt iodine level by rapid test kit were also limitations of this study.

\section{Conclusion}

Prevalence of goiter is found to be high and iodine deficiency disorder is a severe public health problem. In this study being female, elder age, family history of goiter, living in Aykuachakirn and Workmidir increases risk of having goiter in children. Fish consumption and adequate iodine level of salt were protective for goiter. Ensuring the consumption of iodized salt and promotion of fish intake at the household level are highly recommended.

\section{Consent}

Written informed consent was obtained from the patient's guardian/parent/next of kin for the publication of this report.

\section{Abbreviations \\ BCC: Behavioral change and communication; CSA: Central statistical agency of Ethiopia; DHS: Demographic and health survey; FAO: Food and Agricultural Organization; ICCIDD: International Council on Control of lodine Deficiency Disorders; IDD: Iodine deficiency disorders; IEC: Information, Education and Communication; PPM: Parts per million; SNNPR: Southern Nation's Nationalities and People Region; SPSS: Statistical package for social sciences; TGP: Total goiter prevalence; UNICEF: United Nation International Children's Fund; WHO: World Health Organization.}

\section{Competing interest}

The authors declare that they have no competing interests.

\section{Authors' contribution}

MM was the corresponding author and made substantial contributions in conception and design, acquisition of data, analysis and interpretation of data and has been involved in drafting the manuscript. GD Participated in the design of the study and performed the statistical analysis. HG Participated in the design of the study, writing of results and discussion and has been involved in drafting the manuscript. All authors read and approved the final manuscript. MM wrote the paper.

\section{Acknowledgements}

We would like to thank University of Gondar for approval of ethical clearance and technical support for this study. We also acknowledge all staff of Institute of Public Health for their help and courage. Above all our heartfelt thanks go to study participants who spent their precious time in responding to our questionnaire. All data collectors and the supervisors are highly acknowledged for the utmost effort they put to the quality of this research. This research was made possible by the support of the American people through the United States Agency for International Development (USAID) under Agreement No. AID-663-A-11-00017. The contents of this report was the sole responsibility of the Author and do not necessarily reflect the views of USAID or the United States Government.

\section{Author details}

${ }^{1}$ Department of Nutrition, Institute of Public Health, University of Gondar, Gondar, Ethiopia. ${ }^{2}$ Department of Biostatistics and Epidemiology, Institute of Public Health, University of Gondar, Gondar, Ethiopia. ${ }^{3}$ Department of Environmental and Occupational Health, Institute of Public Health, University of Gondar, Gondar, Ethiopia.

Received: 8 March 2013 Accepted: 3 February 2014

Published: 7 February 2014

\section{References}

1. Muirhead S: Diagnostic approach to goiter in children. Paediatr Child Health 2001, 6(4):195-199.

2. Zali MRMK, Azam K, Masgedi MR: Thyroid situation in Iran according to health and disease survey. Iranian J Med Assoc 1994, 13:113-122.

3. Andersson M, Takkouche B, Egli I, Allen HE, de Benoist B: Iodine Status Worldwide, WHO Global Database on lodine Deficiency: Department of Nutrition for Health and Development. Geneva: World Health Organization; 2004

4. Zimmermann MB: lodine deficiency. Endocr Rev 2009, 30:376-408.

5. Delange F: The disorders induced by iodine deficiency. Thyroid 1994, 4:107-128.

6. Hetzel B: The Story of lodine Deficiency: An International Challenge in Nutrition. New York, USA: Oxford University Press; 1989

7. Carmencita David Padilla CF-D: Eliminating iodine deficiency: obstacles and their removal. Ann Acad Med Singapore 2008, 37:45-48.

8. Joint WHO/UNICEF/ICCIDD Consultation: Indicators for Assessing lodine Deficiency Disorders and Their Control Programmes. Geneva: WHO; 1992.

9. Zimmermann MBJP, Pandav CS: Iodine-deficiency disorders. Lancet 2008, 372(4):1251-1262

10. CA WC F' e, van der Haar F, Hautvast JGAJ: Efficacy of oral iodized oil is associated with anthropometric status in severely iodine deficient school children in rural Malawi. Br J Nutr 2000, 84:345-352.

11. Elnour A, Hambraeus L, Eltom M, Dramaix M, Bourdo P: Endemic goiter with iodine sufficiency: a possible role for the consumption of pearl millet in the etiology of endemic goiter. Am J Clin Nutr 2000, 71:59-66.

12. S. Misra SLKJRD: Prevalence of goitre in 6-12 years school-going children of Panchmahal district in Gujarat, India. Indian J Med Res 2007, 126:475-479.

13. Singh MB, Marwal R, Lakshminarayan J: Assessment of iodine deficiency disorders in school Age children in Jodhpur dictrict of Rajasthan. J Hum Ecol 2010, 32(2):79-83.

14. Abuye C, Berhane Y, Akalu G, Getahun Z, Ersumo T: Prevalence of goiter in children 6 to 12 years of age in Ethiopia. Food Nutr Bull 2007, 28(4):391-398.

15. Teklay Kidane AW: Prevalence of lodine deficiency disorder in a highland district in Tigray. Ethip J Health Dev 2006, 20:1

16. Kamath R, Bhat V, Rao RSP, Das A, Ganesh KS, Kamath A: Prevalence of goiter in rural area of Belgaum District. Indian J Community Med 2009, 34(1):48-51. 
17. CSA [Ethiopia] and ORC Macro: Ethiopian Demographic and Health Survey preliminary report. Addis Ababa, Ethiopia and Calverton, Maryland, USA Central Statistical Agency and ORC Macro; 2011.

18. Delange F, Bürgi H, Chen ZP, Dunn JT: World status of monitoring of iodine deficiency disorders control programs. THYROID 2002, 12(10):915-924.

19. Gaitan E: Goitrogens in food and water. Ann Rev Nutr 1990, 10:21-39.

20. Charinet AKU: Determinants of iodine deficiency in school children in different regions of Ethiopia. East Afr Med J 2000, 77(3):133-137.

21. Berhanu N, Michael KW, Bezabih M: Endemic goiter in school children in Southwestern Ethiopia. Ethiop J Health Dev 2004, 18(3):175-178.

22. Jooste JW PL, Kriek JA: lodine deficiency and endemic goitre in the Langkloof area of SouthAfrica. SAMJ 1997, 8(0):10.

23. Ali TZ, Anis RA, Shami SA, Ageer FIF: Prevalence of goiter in school-going children in a Union Council near Islamabad. Pak J Med Res 1999, 38:3-6.

24. Lv S, Zhao J, Chong Z, Xu D, et al: An epidemiological survey of children's iodine nutrition and goitre status in regions with mildly excessive iodine in drinking water in Hebei Province, China. Public Health Nutr 2012, 15(7):1168-1173.

25. Dertia.v.freire maia afm: Sex efect on the familial agregation of endemic goiter. Brazil J Genetics 1981, 4(3):449-457.

26. Abuye COA, Imungi JK: Familial tendency and dietary association of goitre in Gamo-Gofa, Ethiopia. East Afr Med J 1999, 76(8):447-451.

27. Juliane Wicht JSRP: Genetic predisposition for goiters analysed by a case control study in Germeny. Endocr Abstr 2008, 16:715.

28. Hussein IS, Min Y, Ghebremeskel K, Gaffar AM: lodine status and fish intake of Sudanese schoolchildren living in the Red Sea and White Nile regions. Public Health Nutr 2012, 15(12):2265-2271.

doi:10.1186/1471-2458-14-130

Cite this article as: Mesele et al: Prevalence and associated factors of goiter among rural children aged 6-12 years old in Northwest Ethiopia, cross -sectional study. BMC Public Health 2014 14:130.

\section{Submit your next manuscript to BioMed Central and take full advantage of:}

- Convenient online submission

- Thorough peer review

- No space constraints or color figure charges

- Immediate publication on acceptance

- Inclusion in PubMed, CAS, Scopus and Google Scholar

- Research which is freely available for redistribution 